nucleus accumbens, consisting of down-regulation of dopamine receptors in the mesostriatum and hypothalamus. Such a response might result in a reduction in local dopaminergic tone sufficient to produce lethal catatonia, despite mesolimbic hyperdopaminergia simultaneously producing psychosis.

In spite of the great attention these two possibly related entities have received of late, we still known remarkably little about the pathophysiology of either.

AYD, F. J. (1956) Fatal hyperpyrexia during chlorpromazine therapy. Journal of Clinical Psychiatry, 27, 189-192.

Friccione, G. L. (1985) Neuroleptic catatonia and its relationship to psychogenic catatonia. Biological Psychiatry, 20, 304-313.

FrIEDHOFF, A. J. (1983) A strategy for developing novel drugs for the treatment of schizophrenia. Schizophrenia Bulletin, 9, 555-562.

LINDESAY, J. (1986) Neuroleptic malignant syndrome and lethal catatonia. British Journal of Psychiatry, 148, 342-343.

Redlich, F. C. \& Frifdman, D. X. (1966) The Theory and Practice of Psychiatry. New York: Basic Books.

Yale University School of Medicine

J.G. LONGHURST

611 Grace Education Building

25 Park Street

New Haven

Connecticut 06519

\section{Predictors of psychiatric morbidity in cancer patients}

SIR: Harrison \& Maguire's enjoyable review (BJP, November 1994, 165, 593-598) referred to the work of myself and colleagues (Hughson et al, 1986) showing that chemotherapy increased psychological morbidity after mastectomy; they state also that this paper showed that the psychological consequences of radiotherapy after mastectomy persisted beyond six months.

I have never thought that this paper demonstrated persisting psychological morbidity due to radiotherapy. While it compared chemotherapy with radiotherapy, it did not contain a comparison with patients receiving no further treatment after mastectomy. Hence it could not distinguish between the effects of radiotherapy and the effects of having a mastectomy for cancer. However, in a subsequent paper (Hughson et al, 1987) we did compare patients having radiotherapy after mastectomy with those receiving no further treatment. Somewhat to our surprise, we failed to demonstrate any significant excess of anxiety or depression in the patients treated with radiotherapy, although they did show a significant excess of somatic symptoms and social dysfunction.
Despite this negative result, having interviewed all the patients personally, I am in no doubt that a few of them experienced anxiety or even panic caused by going under the radiotherapy machine. But I think that this anxiety was offset by the reassurance other patients got from getting further treatment and from having regular contact with the radiotherapy staff. The control patients having no further treatment after mastectomy had little contact with staff and hence less opportunity to be reassured. The psychological effects of having radiotherapy are more subtle than first appears, perhaps also varying with dosage (our patients did not receive very high doses), and I agree entirely with Drs Harrison and Maguire that further work is needed to look at the effects of radiotherapy for specific disease groups.

Hughson, A. V. M., CoOper, A. F., MCArdle, C. S., et al (1986) Psychological impact of adjuvant chemotherapy in the first two years after mastectomy. British Medical Journal, 293, 1268-1271.

-, -, - et al (1987) Psychosocial effects of radiotherapy after mastectomy. British Medical Journal, 294, 1515-1518.

Leverndale Hospital

A.V.M. HughSON

510 Crookston Road

Glasgow G53 7TU

\section{Worcester Development Project and Powick Hospital}

SIR: Those who worked at Powick Hospital, Worcester (including at least one ex-President of the Royal College), those who took an interest in the Worcester Development Project, and those who happened to read Ian Brockington's and my own book (1991), may be interested to know that the Worcester Development Project story has now finally ended.

It began with the proposition in 1970 that the then DHSS would close a single large mental hospital and replace it with a diverse range of psychiatric facilities in the community as a model national project. The eventual sale of the old mental hospital site would repay the original pump-priming capital invested.

Due to the insistence of all the mental health professionals involved (academic, DHSS and local) the old mental hospital was not closed until the new day hospitals, acute in-patient unit, hostels, etc. had been up and running for some time. The result of that foresight is that - unlike less fortunate areas the citizens of south and mid-Worcestershire have had a viable and modern community-based 